\title{
Coastal Forecasts and
}

\section{Storm Surge Predictions for}

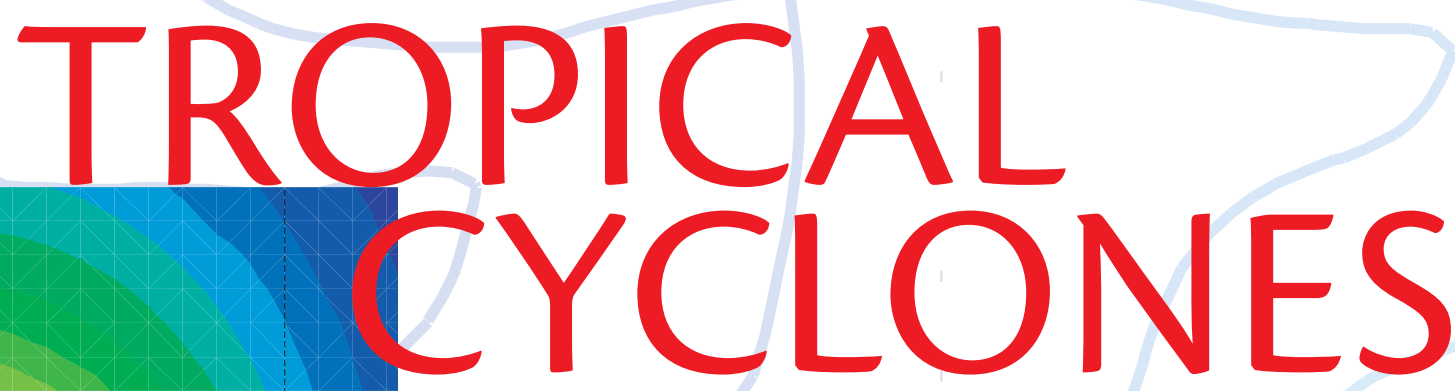

\section{A Timely Partnership Program}

BY HANS C. GRABER, VINCENT J. CARDONE,

ROBERT E. JENSEN, DONALD N. SLINN,

SCOTT C. HAGEN, ANDREW T. COX,

MARK D. POWELL, AND CHARLES GRASSL

The long-term goal of the National Oceanographic Partnership

Program (NOPP) project...is to establish an operational forecasting system for winds, waves, and surge impacting the coastline during the approach and landfall of tropical cyclones. 
$s$ more people and associated infrastructure concentrate along coastal areas, the United States is becoming more vulnerable to the impact of tropical cyclones. It is not surprising, especially after the past two hurricane seasons, that hurricanes are the costliest natural disasters because of the migration of the population towards the coast and the resulting changes in the national wealth density or revenue. A better understanding of both hurricane frequencies and intensities as they vary from year to year and their relation to changes in damages is of great interest to scientists, public and private-decision makers, and the general public.

The estimation of tropical-cyclone-generated waves and surge in coastal waters and the nearshore zone is of critical importance to the timely evacuation of coastal residents, and the assessment of damage to coastal property in the event that a storm makes landfall. The model predictions of waves and storm surge in coastal waters are functionally related and both depend on the reliability of the atmospheric forcing. Hurricane Georges (1998), Ivan (2004), and Katrina and Wilma (2005) are excellent examples of intense tropical cyclones with numerous landfalls and unexpected changes in intensity and movement. Although there are no perfect predictions of the time and location of landfall and the intensity and size of the storm, we are able to forecast wind strength, storm-wave height, and surge levels that are expected along the official track from the National Hurricane Center (NHC) as well as from an ensemble of about a dozen track forecasts that would bracket the results from the least to worst conditions. The variability of these parameters, if known for different forecast tracks, could positively impact the advisories. To be effective and useful, a critical component of any forecast system is its timeliness. 
The long-term goal of the National Oceanographic Partnership Program (NOPP) project described here is to establish an operational forecasting system for winds, waves, and surge impacting the coastline during the approach and landfall of tropical cyclones. The results of the forecasting system would provide real-time information to the NHC during the tropical cyclone season in the Atlantic Ocean, improving advisories for the general public and federal agencies, including military and civil emergency response teams. Therefore, the NOPP forecasting system must be synchronized with the NHC's operational six-hourly forecast cycle. This constraint puts severe demands on computational requirements and resources. This NOPP project utilizes existing modeling capabilities
3. Provide threshold radii for winds and waves.

4. Facilitate risk analysis of expected and maximum conditions.

5. Provide new information for timely advisories.

6. Improve watch and warning zones.

\section{REAL-TIME FORECASTING SYSTEM}

Figure 1 is a schematic of the real-time forecasting system. Real-time data from coastal and ocean buoys, Hurricane Hunter aircraft measurements, and satellite observations, along with model forecasts for track and intensity from the NHC and National Weather Service (NWS), are combined to generate high-resolution wind fields of tropical cyclones along the official and alternate

\section{The results of the forecasting system would}

provide real-time information to the NHC during the tropical cyclone season in the Atlantic Ocean, improving advisories for the general public and federal agencies, including military and civil emergency response teams.

that have been computationally optimized and include data streams and information from the NHC to achieve the following objectives:

1. Develop an integrated, coupled forecasting system for winds, waves and storm surge.

2. Provide deterministic and probabilistic output parameters along alternate tracks. tracks. These detailed wind-fields drive the coupled ocean response models for ocean wave conditions and surge water levels for the approaching hurricane. Results of wind, wave, and surge conditions generated by the forecasting system are available on the web (currently password protected) in graphical formats for different forecast scenarios. The key model components for the NOPP forecast sys- tem of winds, waves, and surge are described in detail below.

\section{Model Grids}

The NOPP forecast system employs three different grids for winds, waves, and surge. The wind-fields are described on a six-minute regular grid, which includes the North Atlantic Ocean, Caribbean Basins, and Gulf of Mexico and extends to $30^{\circ} \mathrm{W}$ on the eastern boundary and from $5^{\circ} \mathrm{N}$ in the south to $53^{\circ} \mathrm{N}$ on the northern boundary.

Hans C. Graber (hgraber@rsmas.miami. edu) is Professor and Co-Director, Center for Southeastern Tropical Advanced Remote Sensing, Rosenstiel School of Marine and Atmospheric Science, University of Miami, Miami, FL, USA. Vincent J. Cardone is President, Oceanweather Inc., Cos Cob, CT, USA. Robert E. Jensen is Hydraulics Research Engineer, Coastal and Hydraulics Lab, U.S. Army Engineer Research and Development Center, Vicksburg, MS, USA. Donald N. Slinn is Associate Professor, Department of Civil and Coastal Engineering, University of Florida, Gainesville, FL, USA. Scott C. Hagen is Associate Professor and Director of Coastal Hydroscience Analysis, Modeling \& Predictive Simulations Laboratory, University of Central Florida, Orlando, FL, USA. Andrew T. Cox is Senior Meteorologist, Oceanweather Inc., Cos Cob, CT, USA. Mark D. Powell is Atmospheric Scientist, National Oceanic and Atmospheric Administration Atlantic Oceanographic and Meteorological Laboratory (Hurricane Research Division), Miami, FL, USA. Charles Grassl is High Performance Computing Technology Specialist, Advanced Computing Technology Center, IBM's T.J. Watson Research Center, St. Paul, MN, USA. 


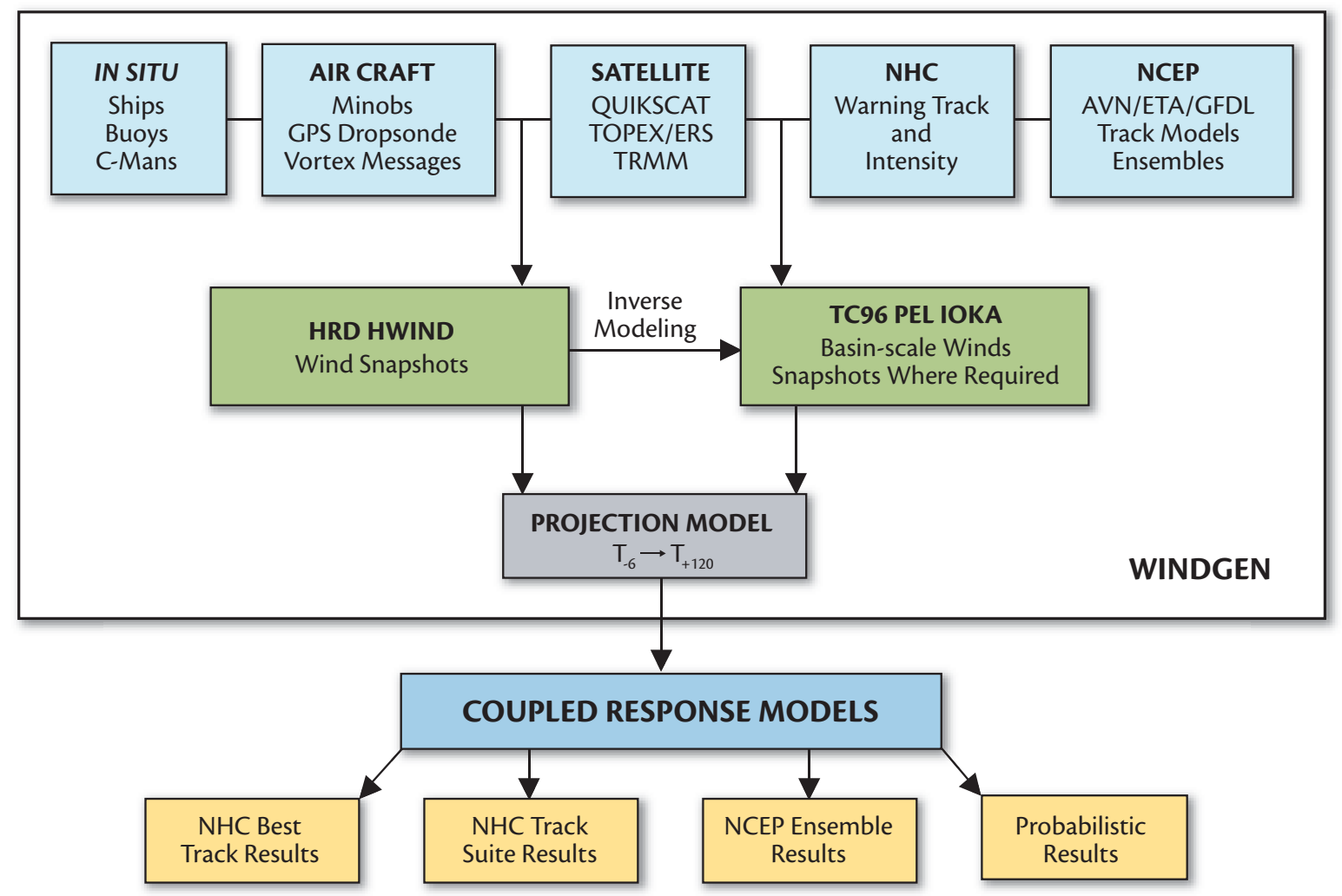

Figure 1. Flowchart of the National Oceanographic Partnership Program (NOPP) real-time forecasting system. Data from buoys, aircraft, and satellites are assimilated in real time, along with model forecasts for track and intensity, to generate high-resolution wind fields of tropical cyclones along the official and alternate tracks. The coupled ocean-response models then generate wave-field conditions and tidal and surge water levels for the approaching hurricane. Results are available in graphical formats for different forecast scenarios on the web (currently password protected).

The ocean-wave model has been implemented on a basin-scale $(\sim 20 \mathrm{~km})$ grid, also covering the same region as the wind model. In the coastal and nearshore regions, we utilize nested high-resolution $(<2 \mathrm{~km})$ grids to include shallow-water effects such as shoaling, refraction, and dissipation by depth-induced breaking and bottom friction. Wind forcing of the wave and surge models is available every 15 minutes to preserve the dynamics and small-scale kinematics of the tropical cyclone. The wave model provides output of mean windsea (short-traveled waves) and swell (long-traveled waves) param- eters as well as full spectral information for boundary conditions to smaller-scale grid nesting. The coastal high-resolution grid will generate output of directionalwave spectra to estimate the wave-damage potential and the radiation stress for coupling with the storm-surge model.

The storm-surge and tidal-prediction models are implemented on a finiteelement grid based on one arc-second high-resolution bathymetry. This finiteelement grid extends only to $60^{\circ} \mathrm{W}$ on the eastern boundary but has been optimized for computational and geometric efficiency. It consists of over 350,000 elements that range in size from tens of kilometers to just a few meters near the coast. Both wind and wave fields are interpolated onto this grid.

\section{Wind Fields}

Hurricane wind-field analyses are generated using WINDGEN, a code that ingests snapshots of the output from the National Oceanic and Atmospheric Administration's Atlantic Oceanographic and Meteorological Laboratory (NOAA AOML) Hurricane Research Division (HRD) Real-time Hurricane Wind Analysis System ( $\left.\mathrm{H}^{\star} \mathrm{WIND}\right)$ and, 
where necessary, the output of a mesoscale numerical dynamical model of the tropical cyclone boundary-layer model. The $\mathrm{H}^{\star}$ WIND wind analysis requires the input of all available surface weather observations (e.g., ships, buoys, coastal platforms, surface aviation reports, reconnaissance aircraft data adjusted to the surface). Observational data are downloaded on a regular schedule and then processed to fit the analysis framework. Data include those sent by NOAA P3 and G4 research aircraft during the HRD hurricane field program, including the Stepped Frequency Microwave Radiometer (SFMR) measurements of surface winds, as well as U.S. Air Force Reserves (AFRES) C-130 reconnaissance aircraft, remotely sensed winds from the polar orbiting Special Sensor Microwave/Imager (SSM/I) and European Remote-Sensing (ERS) satellite, the NASA scatterometer QuikScat and Tropical Rainfall Measuring Mission geostationary satellites. More recently, Synthetic Aperature Radar (SAR) images have been applied to extract veryhigh-resolution wind-fields of tropical cyclones (e.g., Horstmann et al., 2005), which show unprecedented detail of the eye and eyewall morphology, and these images are further applied to predicting hurricane winds.

These data are composited relative to the storm over a four-to-six hour period. All data are quality controlled and processed to conform to a common framework for height (10 m), exposure (marine or open terrain over land), and averaging period (maximum sustained one minute wind speed) using accepted methods from micrometeorology and wind engineering (Powell et al., 1996; Powell and Houston, 1999). This framework is consistent with that used by the NHC and is readily converted to wind load frameworks used in building codes. $\mathrm{H}^{\star}$ WIND ingests these real-time tropical

\section{The estimation of tropical-cyclone-generated}

waves and surge in coastal waters and the

nearshore zone is of critical importance to the timely evacuation of coastal residents, and the

\section{assessment of damage to coastal property in the event that a storm makes landfall.}

(TRMM) microwave imager satellites, and Geostationary Operational Environmental Satellites (GOES) cloud drift winds derived from tracking low-level near-infrared cloud imagery from these cyclone observations measured by land-, sea-, space-, and air-borne platforms into an object relational database and generates high-resolution snapshots of the distribution of hurricane wind speeds' vec- tor wind-fields (Powell et al., 1998).

An alternate, though consistent, set of snapshots of tropical cyclone wind fields are produced by a widely used tropical vortex boundary-layer model, TC96 (Thompson and Cardone, 1996). These winds have been applied directly to tropical and extra-tropical wave model simulations with success (Cardone et al., 1995; Cardone et al., 1996). Although fundamentally a dynamical approach, the TC96 model may be ingested into an interactive objective kinematic analysis (IOKA) methodology (Cox et al., 1992) to better resolve the evolution in space and time of the sub- and mesoscale features in a developing cyclone such as surface wind jet streaks (Cox and Cardone, 2000). Currently, TC96/IOKA is used at times when the $\mathrm{H}^{\star}$ WIND analyses are not available. These snapshots can be incorporated at arbitrary times and on arbitrary grid spacings. A moving-features time-interpolation routine is used to preserve the relative energetics and system's circulation and to prevent smearing of the interpolated wind-fields. The $\mathrm{H}^{\star}$ WIND (or TC96) snapshots are blended into a background wind field using the IOKA objective analysis routine (Figure 2). With a high degree of success, the use of these wind fields in wave-prediction models has produced unprecedented accuracies in the hindcasted skill of storm peak wave heights in extra-tropical storms (Cardone et al., 1995) and tropical storms (Cardone et al., 1996).

Two sets of wind fields ( $\mathrm{H}^{\star}$ WIND and IOKA)are generated by the NOPP model, which complement each other and represent the detailed structure and dynamics of tropical cyclones. The wind fields must be interchangeable, so for 
times when no in situ measurements are available, the IOKA field can be used. The wind fields are used to simulate waves and surge along the different paths from the suite of track-prediction models maintained by the NHC.

\section{Ocean Wave Model}

Providing accurate wave-height estimates for use in appropriate wave-modeling technology is critical. The spatial and temporal scales associated with tropical systems are very short compared to synoptic-scale events (e.g., Nor'easters along the Atlantic coast). The physical processes in these systems, which contain extremely high wind speeds and rapidly turning winds coupled with active windsea and swell interactions, must be accurately modeled. A model that is essentially devoid of adjustment parameters is also a necessary constraint. Ultimately, model selection is based on historical performance in the estimation of hurricane-generated waves. There are many wave models that can generally satisfy these requirements. However, a crucial outcome of the Sea WAve Modeling Project (SWAMP Group, 1985) was the development of third-generation wave models. The main attribute of this class of models compared to their predecessors is that there is no a priori assumption governing the wave spectrum; discrete source terms are included with the same number of degrees of freedom found in the resulting directional wave spectrum. SWAMP and the follow-up activities of the WAve Model (WAM) Group eventually led to the well-known ocean wave model WAM (Komen et al., 1994). WAM is built around the solution to the action balance equation in terms of the action
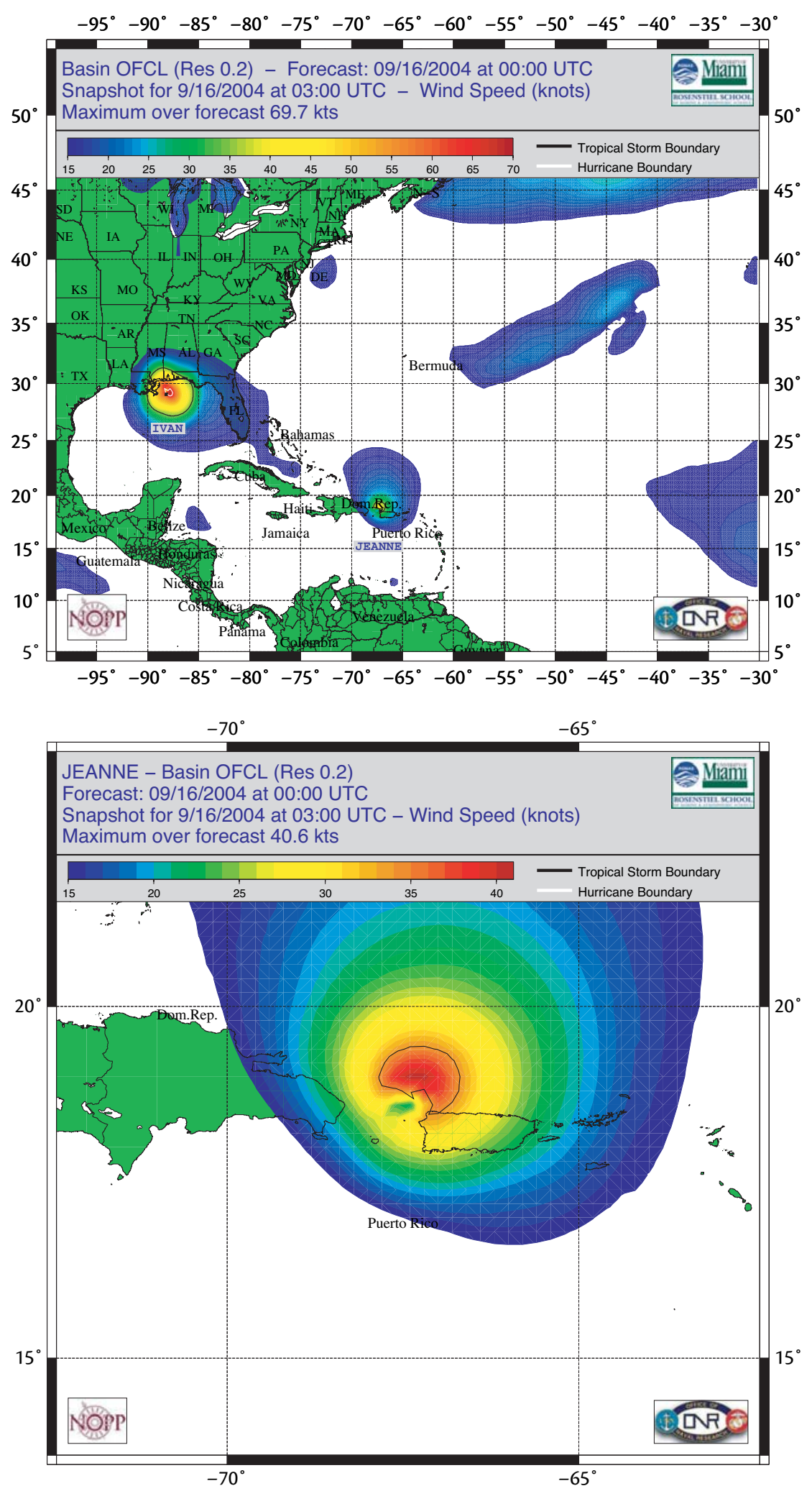

Figure 2. Typical wind-field products generated during the annual hurricane season. Top: Basin-wide map showing all storm systems when present. This example shows Hurricane Ivan close to landfall near Pensacola, FL and Tropical Storm Jeanne impacting Puerto Rico. Black and white boundary lines show threshold values for tropical storm force and hurricane force winds. Note winds below $15 \mathrm{kts}(7.72 \mathrm{~m} / \mathrm{s})$ are not graphed to highlight region of intensive and storm wind conditions. Bottom: Zoomed-in wind field of Tropical Storm Jeanne as she is skirting the western part of Puerto Rico. 
density defined by $F\left(f, \theta, x_{i}, t\right) / \omega$, where $F$ is the energy density spectrum defined in frequency $(f)$ direction $(\theta)$ over space $\left(x_{i}\right)$ and time $(t)$ and the radial frequency $\omega$ is equal to $2 \pi f$. The source-sink terms that add or subtract energy from the wave field are represented by: $S_{i n}$, (atmospheric input), $S_{n l}$ (nonlinear wave-wave interactions), $S_{d s}$ (high-frequency breaking [white-capping]), $S_{w b}$ (wave bottom effects [bottom friction]), and $S_{b k}$ (depthlimited wave breaking).

Over the past three years, WAM has undergone major improvements that have been critical for computational efficiency and dynamic flexibility. Although formulation of the code in pure
FORTRAN90 may be cosmetic, a sophisticated modular system with dynamic loading of memory has made WAM an extremely computationally efficient model. Internal to the model, significant progress has been made, resulting in revised source terms, multi-grid nesting, ice coverage implementation, and, more importantly, depth-limited breaking. In addition, the model has been optimized for scalable computational platforms, reducing the operational constraints by a factor of 20. These improvements, and three years of critical evaluation for the 2003 through the 2005 hurricane season for this NOPP project, including a battery of historical tropical storm simula- tions, have led to the solution of WAM Cycle 4.5 (Günther, 2002) as the technology to be used in this project. Additional insights were gained by recent studies on the cap of the drag coefficient in storm winds (e.g., Powell et al., 2003; Donelan et al., 2004), which led to improvements in the source terms, reducing significant errors in the core of tropical systems by 30 percent. Figure 3 shows an example forecast product produced by the NOPP forecasting system that graphs the maximum wave-height conditions at each grid point over a five-day forecast cycle. This product provides a time integrated view of the maximum wave conditions through a storm.

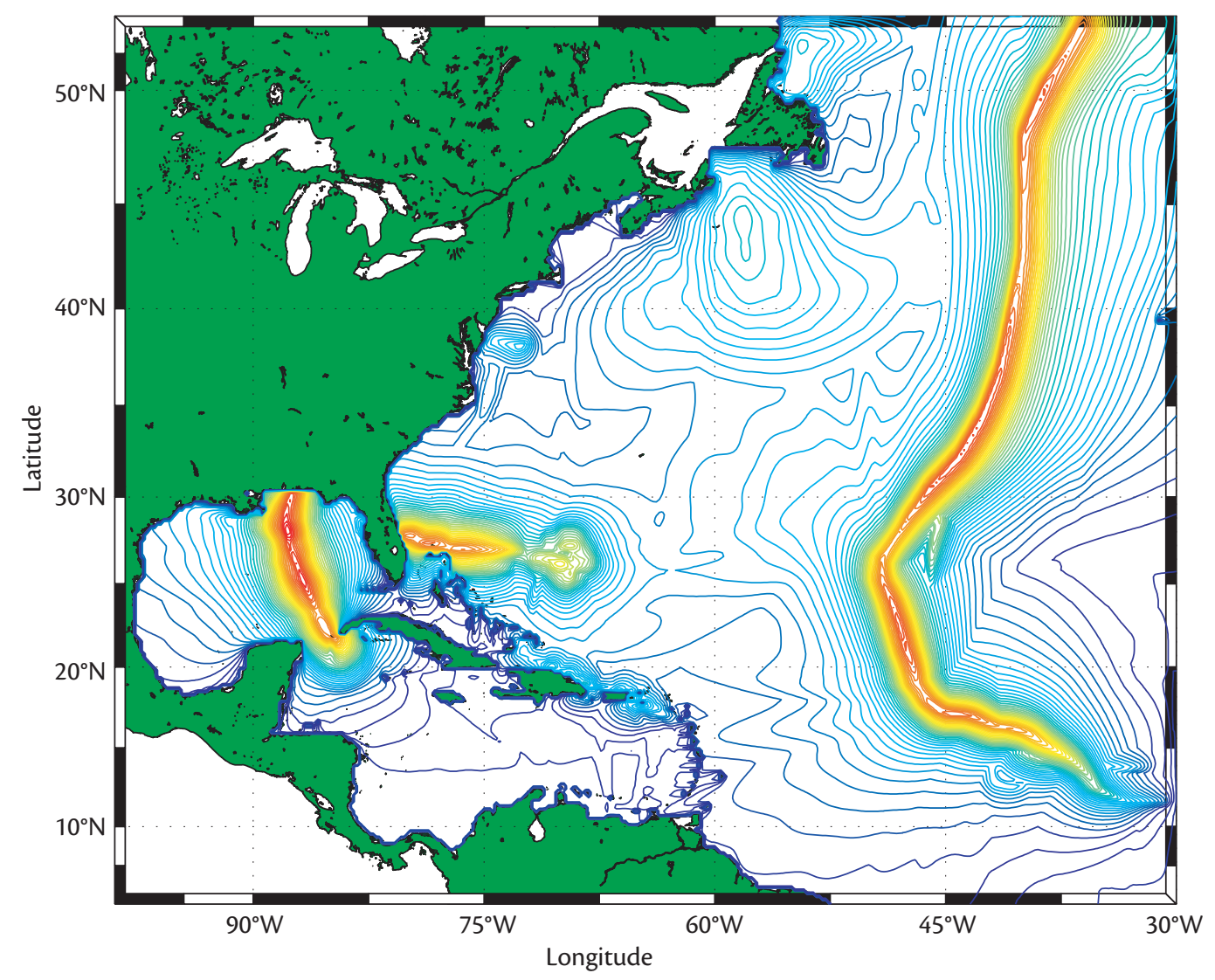

Figure 3. Typical wave-height product generated during the annual hurricane season. The basin-wide map shows maximum wave height conditions over a forecast cycle of five days. This example shows several storm systems, including Hurricane Ivan, as it entered the Gulf of Mexico up to landfall near Pensacola, FL; Hurricane Frances approaching the east coast of Florida; and Hurricane Gaston staying far out in the Atlantic Ocean heading northward. The color bar represents wave height in meters. 
(a)

\section{Storm-Surge Model}

For storm-surge modeling, we employ ADCIRC (ADvanced CIRCulation Model), a finite-element circulation model based on the two-dimensional, depthintegrated shallow-water equations representing the conservation laws for mass and momentum. The momentum equations are combined with the continuity equation and result in the generalized wave continuity equation (Westerink et al., 1993). ADCIRC is implemented in spherical coordinates for this application. There are many parameters that can be set to optimize running the model for specific applications and locations. For example, in coastal regions where there are barrier islands and wetlands, values that specify wetting velocities, depths, and times are critical. Wind-field data are provided in time steps of every 15 or 30 minutes. The associated pressure field is derived from the wind field, if not already available, and is also provided as input. Wave radiation stresses are provided by the ocean wave WAM model to include the wave-induced surge effect. Currently, tidal effects are incorporated by pre-calculating tidal amplitudes and phases along the coastline and adding them linearly.

Model output consists of sea-surface elevation or storm surge and the two-dimensional depth-averaged current field. The forecasted storm-tide elevations are critical for determining the flooding potential of coastal areas that may require evacuations and/or protection. The storm tide is comprised of several components: astronomical tides, wave setup, wave run-up, inverse barometer effect, and wind-driven surge (Figure $4 \mathrm{a}$ ). When a storm approaches, the advanc-

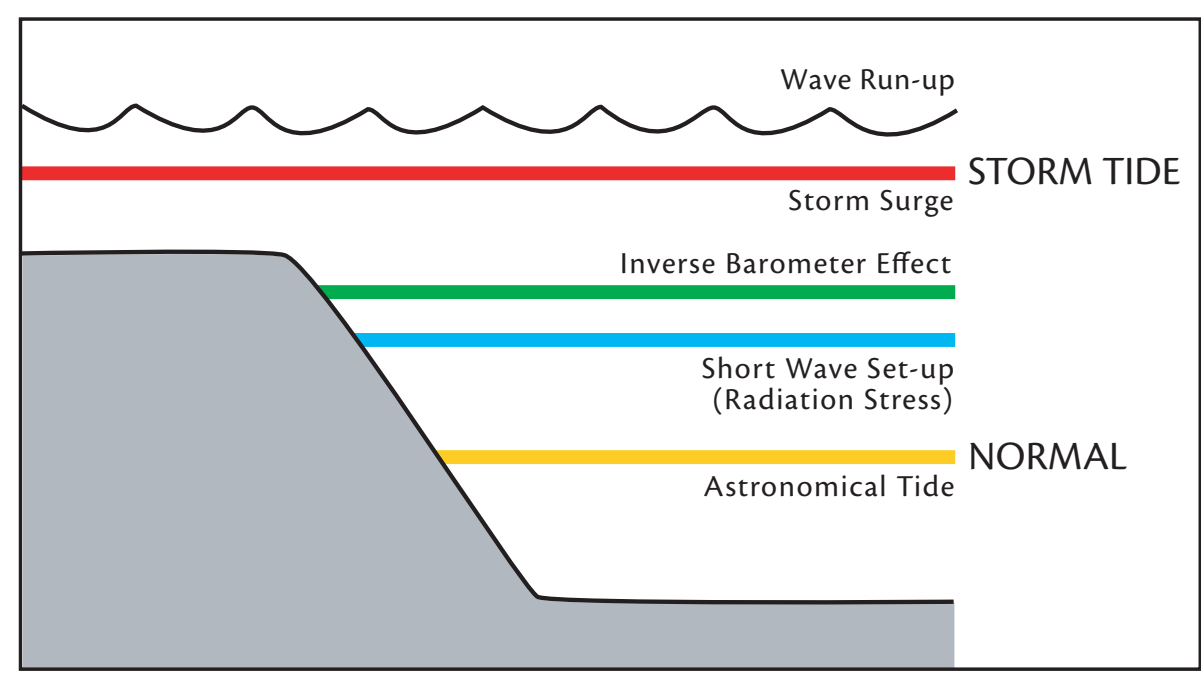

(b)

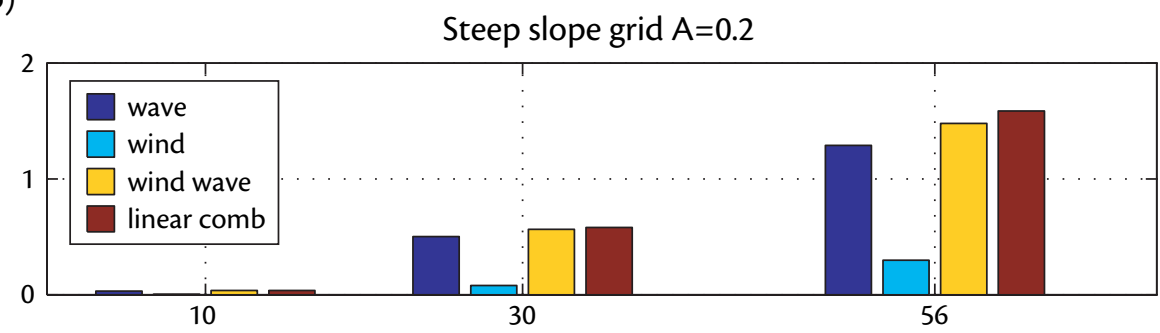

Mild slope grid $\mathrm{A}=0.1$

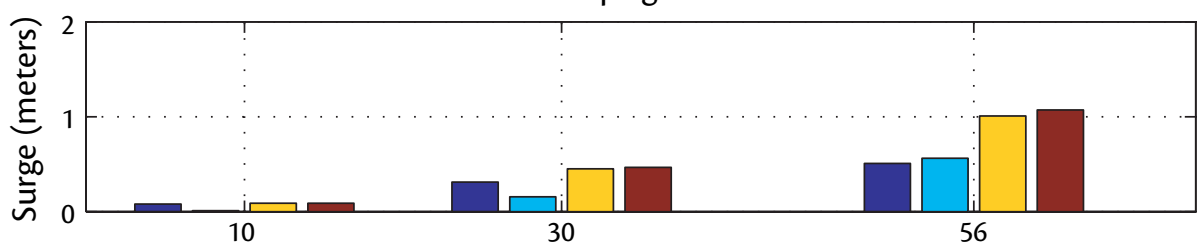

Shallow slope grid $A=0.05$

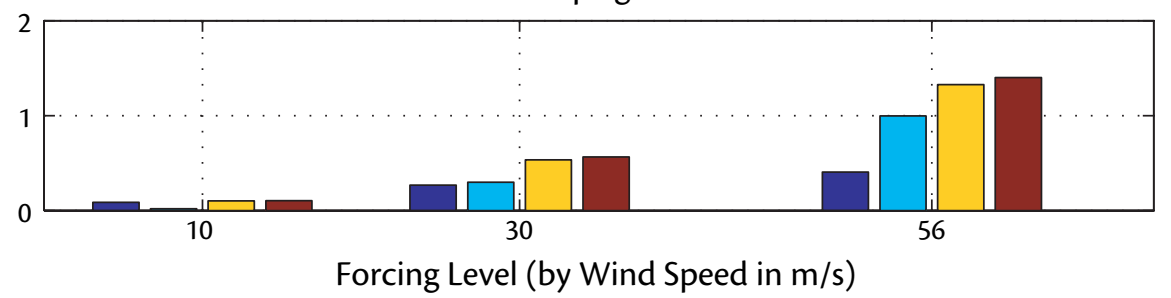

Figure 4. (a) Schematic showing the different contributions of water-level changes that make up the total rise in water elevation (called storm tide). The short wave setup caused by the radiation stress can be as much as the storm-surge effect due to the wind pushing the water up the shore. (b) Storm-surge simulations, including the wave effect, due to radiation stress for steep (top), mild (center), and shallow (bottom) bottom slopes and for wind speeds covering gale $(17.5 \mathrm{~m} / \mathrm{s})$, tropical storm $(26 \mathrm{~m} / \mathrm{s})$, and hurricane $(33 \mathrm{~m} / \mathrm{s})$ force. The simulations show that for steep slopes, the wave-induced water-level rise (dark blue, top panel) dominates the storm surge (wind only) effect (light blue). On the contrary, for gentle slopes, the wind-induced storm surge (light blue) causes the largest water-level rise rather than the waves, which tend to break more rapidly in shallower water. The yellow boxes represent results of total storm surge when wind-driven and wave-induced water levels are added nonlinearly (inside the ADCIRC model), while brown boxes show these results when linearly combined. 
ing waves traveling towards the coast set up a water-level rise; this setup is due to the momentum flux (radiation stress) transferred from the waves to the mean flow. The approaching center of the storm is accompanied by a rapid drop in atmospheric pressure. The change in atmospheric pressure (called the inverse barometer effect) also causes the water level to rise. For example, a $1 \mathrm{mb}$ (millibar) drop in atmospheric pressure causes a $1 \mathrm{~cm}$ rise in water level. The final component is a rise of the water level from the wind pushing directly on the water, or the storm surge. Another contribution comes from the waves running up the beach on top of this already raised water level. Together, all these components make up the storm tide. Currently, not all components are explicitly included in the storm-surge warning provided by NHC or in the Federal Emergency Management Agency (FEMA) maps. Test results using the NOPP forecasting system on modeling. Simulations were performed with three different slopes ranging from steep to gentle, and three wind speeds ranging from gale, to tropical storm, to hurricane-force. The results clearly show that the wave effect can dominate the wind-induced surge for steep beach slopes. In regions with gently sloping bathymetry, the waves lose energy due to breaking caused by steepness and depth limitations. Although for these situations there is still a significant radiation stress contribution, it no longer dominates the water-level rise caused by the winddriven surge.

\section{HURRICANE KATRINA}

As a result of some complex interactions of a tropical wave with the remnant of Tropical Depression (TD) 10, Katrina emerged as a cyclone on August 24, 2005 over the central Bahamas. Rapid strengthening enabled Katrina to quickly attain hurricane status in the later part of

\section{Although there are no perfect predictions of the time and location of landfall and the intensity and size of the storm, we are able to forecast wind strength, storm-wave height, and surge levels that are expected along the official track...}

well-documented historical storms have shown that inclusion of the wave radiation stress can account for as much as 40 percent of the total surge (Weaver, 2004).

Figure $4 \mathrm{~b}$ shows the importance of including wave effects in storm-surge
August 25 within a couple of hours before its center made landfall as a Category 1 hurricane on the southeastern coast of Florida. Katrina briefly weakened to a tropical storm over the Everglades and then emerged into the southeastern Gulf of Mexico on early August 26 just north of Cape Sable, FL.

Once back over the warm waters of the Gulf of Mexico, Katrina re-energized to gain hurricane status. This increase in status was followed by two periods of rapid intensification (defined as a $30 \mathrm{kts}$ [ $15.44 \mathrm{~m} / \mathrm{s}]$ or greater intensity increase in a 24-hour period) between August 26 and 28. About 400 miles (644 km) southeast of the mouth of the Mississippi River a well-defined eye was visible in infrared satellite imagery early on August 27, and Katrina became a Category 3 hurricane with 100-kt (51.48-m/s) winds. Katrina was generally on a westward track due to a strong tropospheric ridge to the north. The combination of this ridge shifting eastward and a midlatitude trough amplified over the northcentral United States allowed Katrina to turn toward the northwest on August 28. A sharply defined, contracted eyewall formed late August 27, which was followed by a second, even more rapid intensification. Katrina jumped from a weak Category 3 hurricane to a Category 5 in fewer than 12 hours, reaching an intensity of $145 \mathrm{kts}(74.65 \mathrm{~m} / \mathrm{s})$ by 1200 UTC August 28. Katrina reached its highest wind speeds of $150 \mathrm{kts}$ (77.22 $\mathrm{m} / \mathrm{s}$ ) at 1800 UTC August 28 about 200 miles $(322 \mathrm{~km})$ southeast of the mouth of the Mississippi River. Figure 5 provides a snapshot of the forecast wind speeds during Katrina's landfall.

Katrina made landfall as a very strong Category 3 hurricane with estimated maximum sustained winds of $110 \mathrm{kts}$ $(56.63 \mathrm{~m} / \mathrm{s})$ near Buras, Louisiana in the early hours on 29 August. Katrina continued northward and made its final landfall near the mouth of the Pearl 


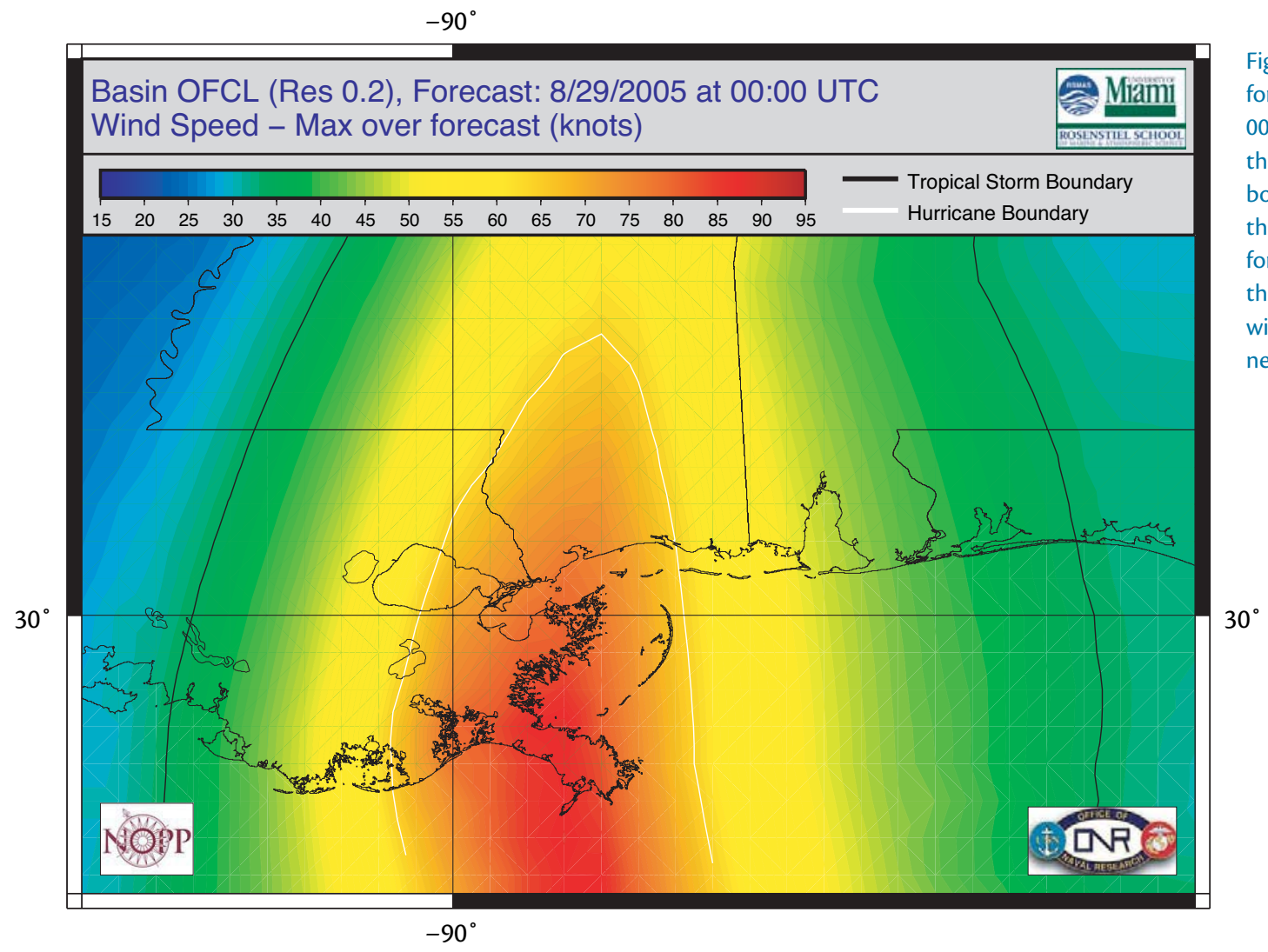

Figure 5. This zoomed wind field forecasted for August 29, 2005 at 0000 UTC shows the boundary of the maximum wind conditions of both hurricane intensity marked by the white line, and tropical-storm force marked by a black line during the time of expected landfall. The winds here represent $10-\mathrm{m}$ height neutrally stable average winds.

River at the Louisiana/Mississippi border, still as a Category 3 hurricane. The rapid weakening of Katrina, just prior to the Gulf landfall, appears to have been primarily due to an eyewall replacement cycle that caused erosion of the inner eyewall while an incomplete new outer eyewall was forming.

\section{WAVE AND STORM-SURGE RESULTS}

The NOPP forecasting system was fully operational and provided forecast winds along the official NHC track as well as all available alternate tracks for up to five days. Three days before landfall in the vicinity of the Louisiana/Mississippi Gulf coast, the forecast system predicted extreme high wave heights surrounding the
Mississippi Delta and storm tides that would cause widespread flooding of the coastal communities. The forecast system was run uninterrupted throughout the entire hurricane season and continued after Katrina made landfall to capture the next tropical storm and/or hurricane. The wave model predicted days in advance the expected high wave conditions approaching the Louisiana/Mississippi Gulf Coast, posing severe threats to the offshore industry and maritime operations and forcing smaller vessel to seek safe harbor or avoid the coastal region. A typical wave-height forecast is presented in Figure 6. These maps were routinely generated for every 15 minutes of the forecast. Nested wave model grids provided high spatial resolution graphics in regions of landfall.

We ran the storm-surge model using the forecast winds and pressure fields along the official track. These fields were used to generate the storm surge (wind component) and inverse barometer effect, which sets up a water-level rise. From the wave model, radiation stress values were computed on the finite-element grid used for the storm-surge model that resolves small inlets, barrier islands, and coastal waterways to correctly predict the wave setup. The results shown in Figure 7 show the maximum water-elevation conditions, which include both the wave effect (radiation stress) and tidal amplitude and phases at three different forecast times six hours apart. The results show that the surge 


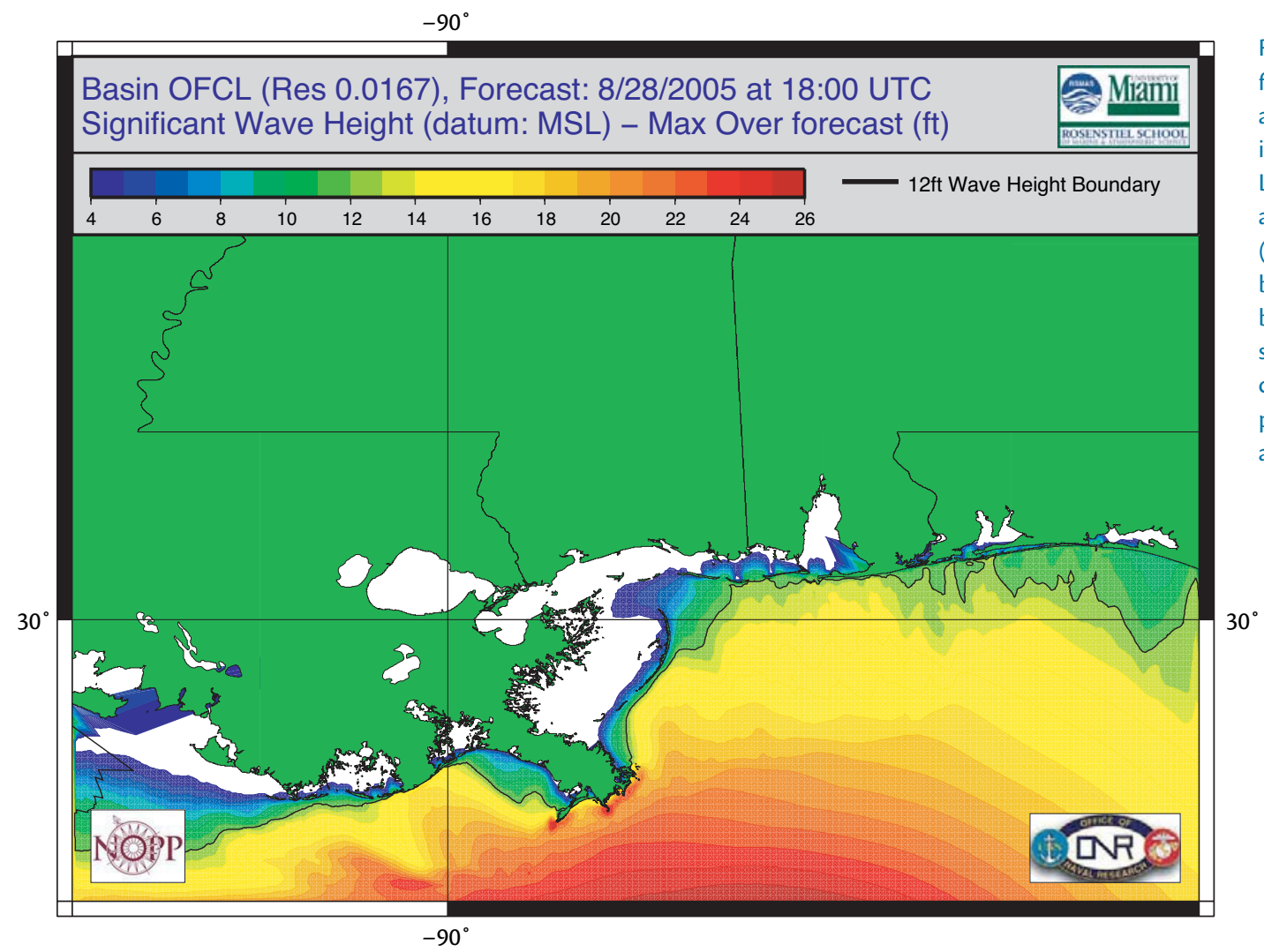

Figure 6. This zoomed wave-height field forecasted for August 28, 2005 at 1800 UTC shows the advancing high waves approaching the Louisiana/Mississippi coastline and the boundary of the $12 \mathrm{ft}$ $(3.66 \mathrm{~m})$ wave height marked by a black (mainly near the coast). This boundary is used for Marine Advisory reports by the National Hurricane Center (NHC). These maps are produced every 15 minutes during a forecast cycle.

concentrated along Lake Borgne and the Mississippi Sound with predicted elevations in excess of $20 \mathrm{ft}(6.1 \mathrm{~m})$. This figure illustrates large surges in St. Bernard Parish, LA and Waveland, MS. Also, high-water levels were generated in Chandeleur Sound and Breton Sound during the passage of Katrina. Highwater levels were also predicted in Lake Pontchartrain, especially along the south side where New Orleans is located.

\section{SUMMARY}

The NOPP real-time forecasting system for winds, waves, and surge has demonstrated the capability to produce timely forecast products up to five days in advance and to run in an operational mode without interruptions for the entire hurricane seasons in 2004 and 2005. The goal is to further amend these forecast products along the official forecast track by the NHC with results from an ensemble of alternate tracks that will generate risk factors of wind and wave exposure and the probability of flooding and inundation of coastal regions.

\section{ACKNOWLEDGEMENTS}

The authors gratefully thank the Office of Naval Research (ONR) and the NOPP office for their support and making this project possible. We also appreciate the support of IBM. We thank reviewers for their helpful comments. Robert Weaver diligently performed the storm surge calculations. Neil Williams and Florence Coquet expertly produced the graphics and maintained the web site (http:// hurricanewaves.org).

\section{REFERENCES}

Cardone, V.J., H.C. Graber, R.E. Jensen, S. Hasselmann, and M.J. Caruso. 1995. In search of the true surface wind-field in SWADE IOP-1: Ocean wave modeling perspective. Global Atmospheric and Ocean System 3(2-3):107-150.

Cardone, V.J., R.E. Jensen, D.T. Resio, V.R. Swail, and A.T. Cox. 1996. Evaluation of contemporary ocean wave models in rare extreme events: The Halloween Storm of October 1991 and the Storm of the Century of March 1993. Journal of Atmospheric and Oceanic Technology 13(1):198-230.

Cox, A., J. Greenwood, V. Cardone, and V. Swail. 1992. An interactive objective kinematic analysis system. A paper presented at Fourth International Workshop on Wave Hindcasting and Forecasting. Environment Canada, Banff, Alberta, Canada.

Cox, A.T., and V.J. Cardone. 2000. Operational system for the prediction of tropical cyclone generated winds and waves. In: The 6th International Workshop on Wave Hindcasting and Forecasting, November 6-10, 2000, Monterey, California.

Donelan, M.A., B.K. Haus, N. Reul, W.J. Plant, M. Stiassnie, H.C. Graber, O.B. Brown, and E.S. Saltzman. 2004. On the limiting aerodynamic roughness of the ocean in very strong winds. Geophysical Research Letters 31(L18306), doi:10.1029/ 
2004GL019460.

Günther, H. 2002. WAM Cycle 4.5. Institute for Coastal Research, GKSS Research Centre Geesthacht, Germany, 43 pp.

Horstmann, J., D.R. Thompson, F. Monaldo, S. Iris, and H.C. Graber. 2005. Can synthetic aperture radars be used to estimate hurricane force winds? Geophysical Research Letters 32(L22801), doi:10.1029/2005GL023992.

Komen, G.J., L.Cavaleri, M. Donelan, K. Hasselmann, S. Hasselmann, and P.A.E.M. Janssen. 1994. Dynamics and Modelling of Ocean Waves. Cambridge University Press, Cambridge, United Kingdom, 560 pp.

Powell, M.D., and S.H. Houston. 1999. Comments on "A Multiscale Numerical Study of Hurricane Andrew (1992). Part I: Explicit Simulation and Verification." Monthly Weather Review 127:1706-1710.

Powell, M.D., S.H. Houston, and T.A. Reinhold. 1996. Hurricane Andrew's landfall in South Florida. Part I: Standardizing measurements for documentation of surface wind-fields. Weather Forecasting 11:304-328.

Powell, M.D., S.H. Houston, L.R. Amat, and N. Morisseau-Leroy. 1998. The HRD real-time hurricane wind analysis system. Journal of Wind Engineering and Industrial Aerodynamics 77/78:53-64.

Powell, M.D., P.J. Vickery, and T.A. Reinhold. 2003. Reduced drag coefficient for high wind speeds in tropical cyclones. Nature 422:279-283, doi 10.1038/nature01481.

SWAMP Group. 1985. Ocean Wave Modelling. Plenum, New York, NY, 256 pp.

Thompson, E.F. and V.J. Cardone. 1996. Practical modeling of hurricane surface wind-fields. Journal of Waterways, Port, Coastal and Ocean Engineering 122(4):195-205

Weaver, R.J. 2004. Effect of Wave Forces on Storm Surge. MS Thesis, University of Florida, Department of Civil and Coastal Engineering, Gainesville, FL, 65 pp.

Westerink, J.J., R.A. Luettich, Jr., and N.W. Scheffner. 1993. ADCIRC: An Advanced Three-Dimensional Circulation Model for Shelves Coasts and Estuaries, Report 3: Development Of A Tidal Constituent Data Base for the Western North Atlantic and Gulf of Mexico. Dredging Research Program Technical Report DRP-92-6. U.S. Army Engineers Waterways Experiment Station, Vicksburg, MS, 154 pp.

Figure 7. The three panels show the storm-surge elevations forecasted for August 28, 2005 at 1800 UTC to August 29, 20050600 UTC every six hours. They show flooding conditions in Lake Borgne and the Mississippi Sound with predicted elevations in excess of $20 \mathrm{ft}(6.1 \mathrm{~m})$ as well as high water levels along Chandeleur Sound and Breton Sound. $\begin{array}{llllllllllllllllllll}1 & 2 & 3 & 4 & 5 & 6 & 7 & 8 & 9 & 10 & 11 & 12 & 13 & 14 & 15 & 16 & 17 & 18 & 19 & 20\end{array}$ $30^{\circ}$

Nopp
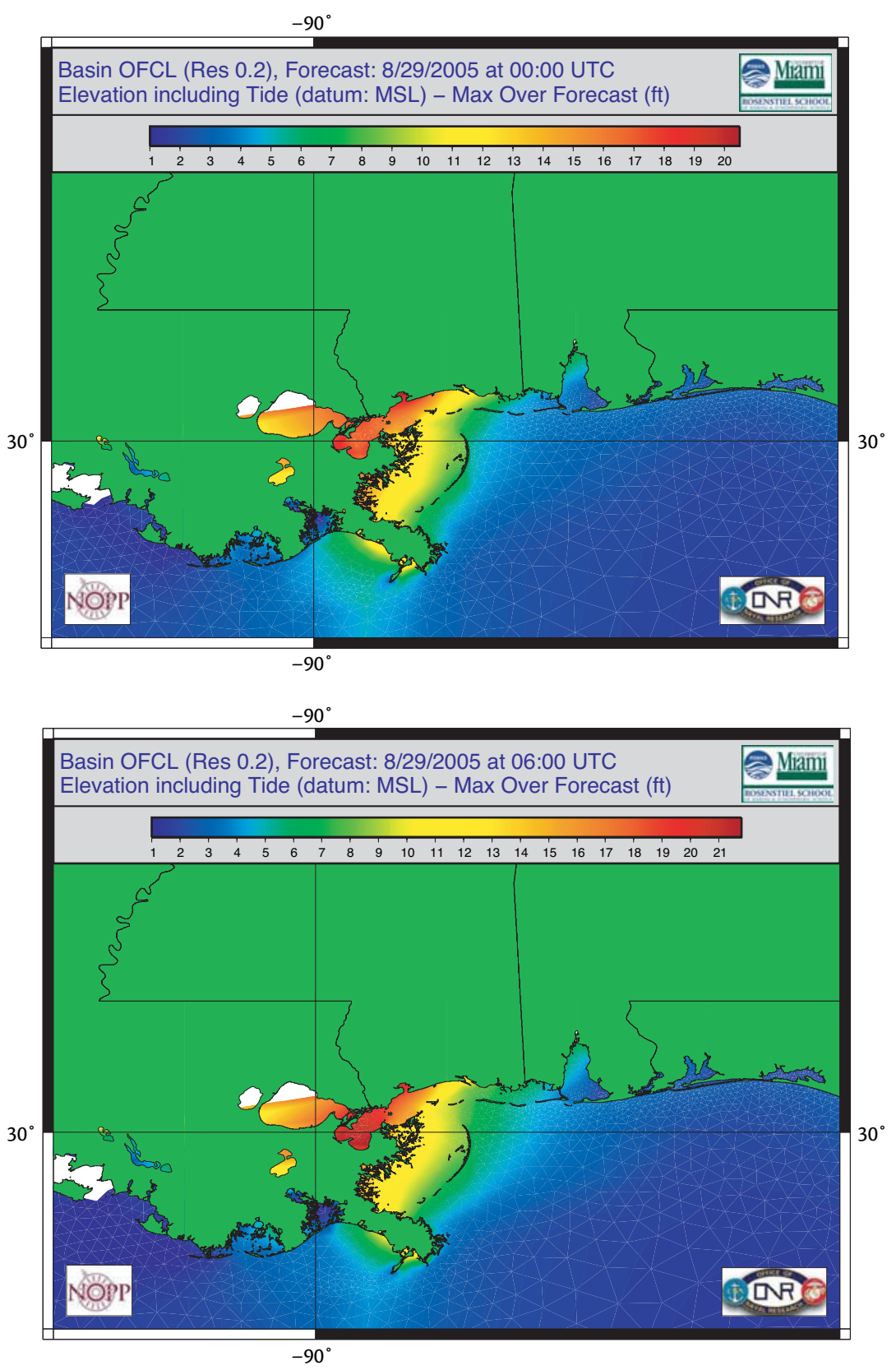